\title{
UNIVERSITYOF
}

FORWARD

THINKING

WESTMINSTER用

WestminsterResearch

http://www.westminster.ac.uk/westminsterresearch

Leveraging Sport Mega-Events: New Model or Convenient Justification?

Smith, A.

This is an author's accepted manuscript of an article published in the Journal of Policy Research in Tourism, Leisure and Events 6 (1-3) 15-30 2014. The final definitive version is available online at: https://dx.doi.org/10.1080/19407963.2013.823976

The WestminsterResearch online digital archive at the University of Westminster aims to make the research output of the University available to a wider audience. Copyright and Moral Rights remain with the authors and/or copyright owners.

Whilst further distribution of specific materials from within this archive is forbidden, you may freely distribute the URL of WestminsterResearch: ((http://westminsterresearch.wmin.ac.uk/).

In case of abuse or copyright appearing without permission e-mail repository@westminster.ac.uk 


\section{Leveraging sport mega-events: new model or convenient justification?}

\section{Introduction}

Sport mega-events are increasingly deployed by urban regimes as social and economic development tools. Various cities have used mega-event projects to address acute issues such as physical degeneration, social dysfunction and economic decline. Critics have derided these efforts as substitutes for effective urban policy, and there is an emerging consensus that mega-events cannot be justified by their impacts alone ${ }^{\mathrm{i}}$ ii. These expensive projects have a track record of underestimated costs and overestimated benefits (Flyvbjerg, 2005; 2007) and there are also concerns about negative impacts such as displacement (of people and businesses), disruption (of everyday life, but also to existing strategies) and the obvious opportunity costs involved. In this context, a more sophisticated approach has been suggested where 'strategies and tactics are implemented prior and during an event to lever desired outcomes (Chalip, 2006). Mega-events are reconceived as windows of opportunity within which to undertake initiatives. As O'Brien (2006: 25) suggests 'events and opportunities they present are merely the seed capital; what hosts do with that capital is the key to realising sustainable long-term legacies'. This approach is usually referred to as event leverage; a concept which is analysed in depth here.

Initiatives have been established to lever a range of effects from mega-events including: increased tourism visitation, small business support, new housing provision, heritage restoration, employment creation, improved healthcare, increased participation levels in the arts/sports, new training opportunities and other forms of 
social development. These effects often rely on parallel initiatives that are pursued in conjunction with an event, with event connections used to boost funding, participation and publicity (Smith and Fox, 2007). This approach is particularly justifiable if the levered benefits relate to the pre-existing goals. Indeed, it is argued that events are often best employed when they are to accelerate existing plans (Smith, 2012).

In this paper, the logic and merits of the leverage model are explored alongside emerging critiques. The realisation that mega-events cannot be justified by their automatic impacts means leveraging has been embraced eagerly by those seeking to justify expensive event projects. Whilst there are few examples where the model has been adopted in its fullest sense (meaning that overly critical judgements are perhaps premature), there is perhaps a danger that event leverage has started to become part of the way mega-events are justified. The budgets for leverage projects are usually disproportionately small compared to the overall costs of staging events and compared to the amount of publicity they receive. Accordingly, there is a need to ensure leverage initiatives are not merely used as public relations tools to deflect criticisms about poor outcomes from event investments.

The overall aim of this paper is to critically evaluate the value of the leverage model for sport mega-events. There are a number of subsidiary objectives and these help to structure subsequent sections of the paper. These are; to identify the essential characteristics of event leverage; to conceptualise different approaches to leverage and to explore the problems and issues associated with these approaches. 
The paper focuses on social and economic leverage, rather than physical or environmental initiatives. Ultimately, the aim is to enhance conceptual understanding, rather than to explore specific cases; but a series of examples are used for illustrative purposes. These are drawn from recent projects adopted in association with the London 2012 Olympic and Paralympic Games (hereafter The 2012 Games).

\section{The logic of leverage}

To identify the essential characteristics of event leverage, the difference between automatic impacts and leveraged outcomes first needs to be acknowledged. The impacts of events are the automatic effects of event projects. Mega-events usually involve substantial investment in capital projects, and they can cause significant social effects. They help to generate jobs, business opportunities and attract visitors that would not otherwise have materialised. Mega-events can also cause unintended and negative effects (Preuss, 2007). Although the distinction is blurry, these impacts are different from outcomes that have been deliberately leveraged by attaching initiatives to events so that they deliver more optimal outcomes. The latter are referred to as leverage initiatives, defined by Chalip (2004:228) as 'those activities which need to be undertaken around the event itself which seek to maximise the long-term benefit from events'. Instead of being an intervention in itself, the event becomes a resource from which wider benefits can be levered. Leveraged outcomes are those which are pre-planned and would have not have occurred without associated 'strategies and tactics' (Chalip, 2006: 112). The notion of leverage is not merely a normative, theoretical one; but one that has been identified through analysing emerging practice. According to Kellett et al. (2008), there has been a subtle, but significant, shift away 
from a focus on event impact to a focus on event leverage. There have been various examples with the 2012 Games perhaps representing the most ambitious suite of leveraging projects ever pursued. A leveraging rationale was evident from the planning stages of the project (Smith, forthcoming) and this approach has been retained post-event. On being appointed the Prime Minister's Legacy Ambassador, Lord Coe stated his ambition was 'to leverage every ounce of economic, social and sporting benefit' (Gibson, 2012).

Although the term is derived from financial strategy (VanWynsberghe et al., 2012), the conceptual origins of events leverage are better understood by making links to ideas developed within the field of sponsorship. Leverage can be related to the notion of 'activation' a concept which highlights that positive action needs to be taken in association with events to achieve desired effects. As Papadimitriou and Apostolopoulou (2009: 95) identify, activation involves extra investment by the sponsor on top of the basic fee 'to create programs that will take advantage of the rights gained'. This essentially means undertaking activities to maximise the opportunity and to strengthen the relationship between the sponsor and the event. The work of Chalip (2004; 2006) and O'Brien (2006) suggests they conceive more general events leverage as following a similar rationale and process.

\section{Different approaches to event leveraging}

Leverage initiatives tend to take a variety of different forms not simply because they aim to achieve different types of objectives, but because of their variable prominence and scope, and the different ways they are linked to the events which inspired them. It 
is important to acknowledge these differences because some approaches to event leveraging may be more likely to achieve positive outcomes whilst other types are more likely to act as part of the justification for mega-events.

Most mega-events are staged for political reasons - to enhance the status of a host city and the reputations of people in positions of power. Other objectives are often secondary considerations and, in these instances, leverage projects tend to be given less prominence. In these instances, leverage projects may be used to help justify large capital investment projects, to help placate opposition and to improve public relations. In more enlightened projects, key strategic objectives - such as addressing territorial inequity, social problems or economic malaise - are core in the rationale for staging the event. In these latter cases there is an opportunity for leveraging to be central to the event project, rather than something that is considered merely as a supplementary dimension.

The prominence of leverage initiatives within the event programme is also related to the issue of when event leverage objectives and strategies are formulated. In many projects leverage is an after thought - initiatives are bolted on to an event after key decisions have been made. Once host cities start to realise that they may not achieve the impacts they had promised, there is a tendency to put together a set of leveraging projects that could improve the outcomes of the event. A more progressive approach is to integrate leverage from the bid stage of a mega-event, with subsequent project design influenced heavily by the ambition to lever certain outcomes. This allows leveraging to become the 'model' for the strategic use of the event, rather than merely supplementing a traditional top down / impact-led / trickle down approach. 
In most mega-events the vast majority of the budget is spent on building venues and staging the event, with wider projects and leverage initiatives allocated a relatively small proportion of funds. In more enlightened examples, capital investment costs are restricted - allowing more funds to be dedicated to achieving wider policy goals through leverage projects. A good example is the 2006 Melbourne Commonwealth Games. The city already had the key venues in place so the organisers were in the fortunate position of being able to focus on wider social policy objectives such as: promoting diversity, accessibility, inclusive employment opportunities, community cohesion and active communities (Kellett et al., 2008). However, in most other megaevents there is a large discrepancy between the size of the event budget and the resources allocated to leverage initiatives. This leaves organisers prone to accusations that leverage is merely a form of tokenism used to fend off criticism of event spending, rather than an integral part of the event project. Manchester's leverage initiatives delivered in association with the 2002 Commonwealth Games have been praised for their innovative and progressive approach and their positive outcomes (Smith and Fox, 2007). But the cost of these initiatives was $£ 17.7$ million (Smith and Fox, 2007) - a relatively small figure compared to the capital investment in venues estimated to be c.£200million (Gratton et al., 2005).

Some leverage projects are inextricably linked to events - they rely on events and they try to extend the positive impacts that we would normally expect from event projects. Applying the definitions developed earlier, this is event-led leverage. Examples include initiatives that try to ensure that local businesses are able to secure some of the contracts associated with events (Chalip, 2004). This type of leverage 
aims to regulate and manipulate the impacts of events to optimise outcomes. These initiatives could not exist without an event. They attempt to maximise the effects of different activities normally associated with staging an event. Other leverage projects have much looser links with events. These are often general initiatives designed to capitalise on the opportunity of the mega-event. The outcomes of these projects would not normally be expected from events - they are the result of imaginative leveraging that seeks to harness the power of events (in particular their symbolism, timing, prominence and popularity). This is something that often relies on the festivity associated with events (rather than their specific content). Benneworth and Dauncey (2011) regard events as 'symbolic-emotional' narratives and this is a useful term because it emphasises why events can achieve effects above and beyond those we could expect to see from more conventional policies. Major events are riddled with imagery and symbolism and they provoke passionate and emotional responses from many people. The aim of recent host cities has been to try and harness these characteristics to theme wide policy initiatives. Unfortunately, this is still a rather speculative process. As Benneworth and Dauncey (2011: 1095) identify, we still 'need to know more about the conditions by which symbolic-emotional narratives become significant in shaping urban development trajectories'.

Smith and Fox (2007) differentiate between 'event-themed' regeneration and 'eventled' regeneration. In event-led leverage, the aim is to extend and optimise event impacts. In event-themed projects, a wider set of non-essential programmes are pursued - with the event used as a hook to achieve more interest, higher rates of participation and, hopefully, better outcomes. Examples of event-themed leverage initiatives include some of the projects associated with the (2002) Commonwealth 
Games in Manchester where the event was leveraged to achieve outcomes such as new Healthy Living Centres, extra-curricula activities for disadvantaged school children and more capacity to stage cultural festivals (Smith and Fox, 2007). These initiatives help to clarify the difference between 'event-led' leverage and 'eventthemed' approaches. Both are forms of leverage - it is just that the relationships between events and the initiatives are configured differently. In the event-themed approach, projects are designed and organised to address key priorities, whereas event-led leverage aims to optimise event impacts.

\section{A new model?}

A key difference between leveraged events and conventional events is that in the former the starting point (and focus throughout) is what stakeholders asscoiated with the host destination want to achieve. The aim is to avoid being led and restricted by the requirements of the event, especially as these are often determined by outside interests that do not have a long-term stake in the host city (Smith, 2012). To some extent, host cities have always had an eye on what they might achieve by staging events and have designed them accordingly. In this sense, one could argue that leveraging is simply the formalisation and naming of something that has long existed. Seeking to consolidate this approach into a model helps to provide useful guidelines for future practice, but there is a danger that like other event models (e.g. the Barcelona model) complex policy initiatives are oversimplified and decontextualised, leading to an unthinking transfer of policy lessons (Gonzalez, 2011). 
For Ziakas (2010) leverage does not merely provide a revised model but a 'paradigm shift'. Whilst this might seem hyperbolic, there is something both coherent and innovative about Chalip's (2004) suggestion that events should be seen as opportunities for interventions not interventions in themselves. Another key difference between leveraging and traditional approaches to event planning is that leveraging aims to produce a forward thinking, strategic approach where both the impacts and the ways to achieve them are planned in advance of an event. This is why O'Brien and Chalip (2007: 297) describe leveraging as 'more strategic ex ante, analytical approach' rather than one that has an 'ex post, impacts-driven, outcomes orientation'.

A further innovative quality of event-themed leverage is that it can help host cities to transcend a top down approach dominated by interventions that assume that economic impacts and social benefits will 'trickle down' to those most in need (Smith and Fox, 2007). By adopting leverage initiatives, host cities can move towards a model that has more in common with a bottom-up approach. The record of large-scale, top-down interventions is very poor, and event-themed leveraging allows mega-events to be aligned with a more enlightened development model that is more focused on the needs of target beneficiaries. Projects can be designed and implemented at the neighbourhood level - with the mega-event used merely as a theme to assist projects. By supplementing top down interventions (the event project) with bottom-up initiatives (leverage), the idea is that the benefits of each approach can be realised.

One of the other essential justifications for a leverage approach is that pursuing projects in association with mega-events means positive impacts can be delivered to 
different groups of people and in extended policy fields, geographical areas and time periods. These ideas are discussed further below.

Extending the reach of mega-events (thematically, socio-demographically, geographically and temporally)

One criticism of sport mega-events is that they can only deliver a limited range of positive impacts. Leverage initiatives can be used to extend the reach of these events into domains that might be otherwise unaffected. Early leverage approaches attempted to achieve wider physical regeneration. For example, staging a mega-event (the summer Olympiad) was used as an opportunity by Rome (1960) and Tokyo (1964) to make fundamental changes to urban infrastructure. Later projects tried to leverage mega-events to complete long term urban development plans (Barcelona's 1992 Olympic Games). In the contemporary era, there has been a greater focus on social and economic leverage (Chalip, 2006; Preuss, 2007; VanWynsberghe et al., 2012). The most commonly deployed projects seem to be those which aim to enhance community cohesion, encourage volunteering, increase employability, assist educational achievement, encourage healthier lifestyles and help persons with a disability (Smith, 2012). The range of objectives that could be linked to mega-events seems almost limitless. It is now difficult to think of a policy goal that couldn't be pursued via a well designed event-themed project. However, more research is required to understand whether effects are diminished if the links between the megaevent and the wider policy initiatives are viewed as tenuous. If an event is conceived as a useful theme or hook with which to frame initiatives then we would presume that the policy fields most closely linked to the event (e.g. sports development in the case 
of a sport mega-event) would be those where event-themed leverage projects would be most likely to succeed. However, there is some evidence that strong links are not a crucial determinant of success. The evaluation of the work of the Legacy Trust which distributed $£ 40$ million to UK arts, cultural and education projects in association with The 2012 Games - concluded that: 'The Trust has been highly successful in creating a lasting cultural and sporting legacy'; even though a large proportion of participants did not even know their project was linked to The 2012 Games (Legacy Trust UK, 2012: 49).

Increasing the range of socio-demographic groups that benefit is also an example of how leverage can be used to extend the reach of events. Research has shown that the benefits of mega-events tend to elude the most disadvantaged groups in society (Newman, 1999; Porter et al., 2009). This problem is exacerbated because these groups are often those most affected by the negative impacts of staging mega-events including displacement, rises in costs of living and cuts to welfare spending (Watt, 2013). Many event bids use disadvantaged people as a justification for why an event is needed and why a certain city should win an event (Carey et al., 2011). But without dedicated leverage initiatives, it is rare that these groups will see any of the benefits.

The automatic impacts of mega-events are usually spatially concentrated. Even though an event may be funded at the national or regional level, positive impacts tend to be experienced in a relatively confined geographical area. Therefore, leverage projects often aim to extend the geographical reach of effects. Adopting leverage initiatives can mean that mega-event projects assist target areas even if those areas are situated away from the main event site(s) (Smith, 2009). However, the problem (cited 
above) of tenuous event links may also be relevant here. More research is needed to understand whether proximity to an events site is a critical success factor in event leverage. If proximity is not significant then this highlights an opportunity, but it also raises a whole set of further questions. If remote leveraging is effective, then it may be more expedient for cities to develop leverage initiatives in association with events that are being staged (and funded) by other cities, including those hosted in other countries. This geographical diffusion can also work with other way round; increasingly host cities are using international legacies as part of the justification for staging mega-events. One the lesser known initiatives pursued in conjunction with the 2012 Games was the 'International Inspiration' programme which aimed to deliver a sports development legacy in twenty countries around the world ${ }^{\mathrm{iii}}$.

A noted problem with mega-events is that they are temporally contained: they often only deliver positive impacts in a confined time period. Therefore, leverage can also be used to ensure that positive outcomes are achieved at times when they wouldn't otherwise occur. It is now common for host cities to adopt projects that deliver positive outcomes in the pre-event period (e.g. employment, skills and training) as well as those that occur during and after the event. Local Olympic Organising Committees in Vancouver and London both implemented a Legacy Now programme (an idea conceived by Toronto in their Olympic bid for the 2008 Games) that aimed to deliver a pre-event legacy of training, skills development and employment experience in the build up to the event. Leverage projects can also be used to extend the positive effects of events for a longer period after the event than would otherwise be the case. Some of the positive impacts of mega-events (e.g. image enhancement, community cohesion), can quickly dissipate unless projects are developed to maintain momentum. 
Leverage projects can also be adopted to deal with some of the negative 'hangover' effects that result from a mega-event's temporal concentration - such as the noted drop off in employment levels after events are staged, over-supply in the hotel and housing sectors and the anti-climax felt by many citizens. However, it should be noted that leverage initiatives may be similarly prone to temporal problems. Even though projects may be scheduled for the periods before and after events are staged, if these are reliant on event connections then they may also be subject to temporal constraints. With respect to the pre-event period, building interest and engagement too far in advance of the opening ceremony is difficult. Furthermore, evidence from some events suggests staff and resources - as well as levels of interest - tend to drift away once events have been staged (Smith and Fox, 2007). This means event leverage projects, as well as event projects, may also be vulnerable to temporal limits and hangover effects.

\section{Summarising the different approaches}

\section{INSERT FIGURE 1 HERE}

The preceding discussion highlights the different ways that leveraging has been undertaken by host cities. Many projects attempted thus far have been peripheral, small scale efforts designed to supplement wider investment in mega-events. Often these projects are configured relatively late in the life cycle of an event and their budgets are dwarfed by the concurrent investment in capital projects. Projects with these characteristics are vulnerable to criticism that they exist mainly as tokenistic efforts designed to deter local opposition and dampen press criticism. If we are to 
envisage leveraging as a new model for event projects, then a more comprehensive and generous version of leveraging needs to be adopted. To be regarded as a new approach to mega-event planning leveraging needs to be a central organising principle rather than an after-thought. It needs to be part of the criteria for assessing bids, an integral part of decision-making processes in the early stages of event planning and the resources available need to match those for venue projects. Cities need to be more selective about the events they bid to stage, with the choices based on which events provide the best opportunities to lever the outcomes they seek. But rather than merely extending the effects of events, leverage can also deliver outcomes that are not reliant on events themselves. The risk of overly event-led projects is that initiatives become led by the requirements of the event, rather than the directions host cities wish to pursue. This contradicts one of the essential aspects of leverage.

The notion of event-themed leverage outlined in Figure 1 is conceptually clear, but the practicality of implementing this model is somewhat questionable. Advocating a recasting of events as more coherent interventions conveniently ignores the complexity and politics of events; in particular the multiple objectives and multiple stakeholders that need to be satisfied. Staging mega-events has always been a messy process with fuzzy outcomes, and although we are now seeing more sophisticated initiatives, messiness / fuzziness remains an integral part of events projects. There will always be an element of ad hoc opportunism in events strategy making; and for projects that are developed over an extended period it seems impossible to avoid drifting from original strategic aims. Therefore, even if we can outline a new model of event leverage, this remains a normative concept rather than one that can be easily delivered. 


\section{Issues and problems with leveraging}

In previous sections of this paper the logic of leveraging has been explained and different leveraging approaches outlined. In the next section several problems and issues with leveraging are explored, providing a basis for conclusions about the overall potential and implications of mega-event leveraging.

\section{Who should undertake leveraging?}

An interesting question regarding the formulation of effective leverage initiatives is who should design and implement them? Event leverage initiatives are separate from, but related to, the delivery and management of event projects. This makes it awkward to allocate responsibility for their design and implementation. It is advisable for organisations that have expertise (and a long term stake) in the relevant policy fields to deliver projects. This means, for example, that social projects should be led by local authorities and / or third sector organisations and economic projects by local economic partnerships. Examples of local authority leadership include The Greenest City initiative pursued by the City of Vancouver in conjunction with the 2010 Winter Olympic Games (VanWynsberghe et al., 2012) and the 'adopt a second team' initiative pursued by Melbourne municipal authorities in association with 2006 Commonwealth Games (Kellett et al., 2008). However, as leverage projects rely to some extent on events, there has to be some formal involvement of local organising committees and affiliated events agencies. These agencies are often limited life 
organisations focused on specific logistical and management issues. This means they are not ideally suited to leading long term social and economic development projects.

There are various advantages and disadvantages of involvement from event agencies. Too much involvement means that leverage simply becomes a subsidiary extension of existing event projects i.e. it is automatically event-led. But event leverage that is too detached from the management of an event may struggle to lever the event in an optimal manner. In independent leveraging projects, those responsible find it difficult to maximise opportunities created by staging mega-events - for example they may not be able to make use of new facilities, branding and tickets and they may not be able to negotiate privileged access to some of the opportunities (e.g. employment, volunteering) that arise from staging events (Smith and Fox, 2007). Ultimately, effective leveraging depends on partnerships between community stakeholders and event managers (Ziakas, 2010).

\section{Funding}

There are also other concerns about the emerging leveraging model. Although the cost of social leverage initiatives may be relatively small compared to the overall costs of staging a major event, they do add to the overall financial burden. Of course, the idea is to make the most of the opportunity. But if projects are unsuccessful or if they rely too heavily on events that are unsuccessful, host cities can be accused of unnecessarily adding to the costs of staging an event. For example, one high profile critic of The 2012 Games suggested that the organisers' 'big mistake' was 'was to tip into their budget a mass of feel-good junk about legacy' (Jenkins, 2007). One way for 
host cities to offset the extra costs of leveraging is to ensure that this model is adopted alongside a decreased commitment to capital investment in venues. This fits with the one of the innovative features of the leverage model: focusing on the desired outcomes of the staging the event, rather than the event itself.

Delivering effective event leverage initiatives means accessing adequate funding. If leverage work is funded via the overall budget for an event this can result in projects being jettisoned if there are budgetary problems. Events are infamous for their tendency to go over-budget and this means that some leverage projects never get implemented. The preparations for the London 2012 Games provide a useful example. In 2011, the UK's Department for Media, Culture and Sport announced that a scheme to use the Olympics to inspire people to volunteer to do unpaid work in their community was to be scrapped. The project - called the $25^{\text {th }}$ hour - was discontinued (at the $11^{\text {th }}$ hour!) because it was considered to be 'too expensive and lacking focus' (Beard, 2011). In alternative models, funding is provided independently of event budgets. Manchester's Legacy Programme attached to the 2002 Commonwealth Games (which included an innovative volunteering scheme) was funded separately from the event management agency. Nichols and Ralston (2012: 179) suggest that this meant 'there was no possibility of funds being diverted from delivering a legacy to delivering the Games'.

Event sponsors represent an alternative source funding for leverage initiatives. In an era when corporate responsibility is a priority, companies like to be associated with environmental and social initiatives and so related leverage projects are often paired with relevant sponsors. In the case of the 2012 Games sponsors provided support - 
both financial and in-kind - for initiatives that would not have otherwise been implemented (Dowling et al., 2013). It is too simplistic to assume sponsors are selfishly seeking competitive advantage when sponsoring mega-events (Papadimitriou and Apostolopoulo, 2009). However, corporate sponsors are not always appropriate partners of leverage initiatives and this problem is exacerbated when companies try to influence the direction of these programmes. A good example was the Young Leaders project - part of 'Get Set': the London 2012 Games education programme. This was sponsored by BP. The idea was to give 100 young people from disadvantaged backgrounds the chance to participate in an intensive 18 month personal development programme. This would allow them to play an active role in leading and promoting projects within their own communities. However, when the programme is analysed more closely it appears that candidates were selected based on the basis that they lived close to one of BP's four hub locations: Hull, Aberdeen, Canary Wharf or Sudbury on Thames. Therefore, aside from the ethical dilemmas associated with connecting social programmes to discredited oil companies, sponsors tend to want to direct schemes rather than simply fund them. There remains the danger that these schemes do more to improve the reputations of the companies that sponsor them than they do to assist wider objectives. Levermore (2011: 891) is even more sceptical - describing sponsor funded programmes adopted in association with the 2010 World Cup as 'weak' and 'unlikely to result in a win-win situation for society or business'. According to Levermore (2011), event-led schemes are inherently short-lived because of their links to a one-off event; compromising their benefits. Even when sponsor programmes are conceived more in line with event-themed leverage, Levermore (2011) suggests that intended outcomes are weakened by the tenuous links with the mega-events they are attached to. 


\section{Branding}

Developing event-themed leverage initiatives to pursue wider objectives may represent a new model for event projects, but there are problems and disadvantages associated with this approach. One issue is the restrictions usually placed on using event brands. Most leverage initiatives rely on publicising event connections. But to protect event brands and sponsorship revenues, rights holders and local organising committees tend to prohibit the use of official logos, certain wording and event associations. This means that projects led by organisations other than rights holders and local organising committees (and their sponsors) are often unable to make official connections to events. For example, the London 2012 Games 'Changing Places' programme helped communities surrounding the Olympic Park to undertake small projects that enhanced their local area during the run-up to the Games. However, those submitting grant applications were instructed that the name of their project should not include any of the following: Olympic, Olympian, Olympiad, Paralympic, Paralympian, London 2012 or 2012. These types of restrictions make it very difficult

to use the hook of the Games to frame 'unofficial' projects. The International Olympic Committee is notoriously protective of their brand(s), but this is not merely an Olympic problem - it also applies to other event franchises. In research regarding the opening stages of the 2007 Tour de France (staged in London), local areas found it difficult to promote various initiatives because of the limits placed on the use of the race brand (Smith, 2008). 
Problems regarding branding restrictions are not insurmountable. Compromises have been reached that protect the interests of sponsors, but which allow other organisations to use event associations to theme social regeneration projects. Many of these initiatives take advantage of multi-tiered branding - something used in contemporary mega-events to help differentiate between different levels of sponsorship. In the case of the London 2012 Games, the Inspire Programme was adopted. Non-commercial organisations that had developed Games-inspired projects were invited to apply to the scheme. Successful applicants were able to use a specific $\log 0$ - a subsidiary version of the $2012 \log$ o that indicated that a project had been 'Inspired' by the Games. One of the great advantages of this scheme was that eligible projects could still use and apply for the branding during the post-Games period. Even if organisations cannot access either official or subsidiary branding they can still allude to event links without contravening licensing restrictions. In the case of the 2007 Tour de France mentioned previously, local authorities in London were given advice by the local organisers about using cycling imagery and colouring that inferred a connection with the event, but which used neither official logos nor wording (Smith, 2008).

\section{Research and evaluation}

The potential problems associated with adopting event-themed leveraging as a core part of event legacy planning also include important research issues. One of the knock-on effects of leverage initiatives is that they make the task of evaluating the outcomes of events more difficult. Researchers now find it hard to separate the impacts of the event from the effects of supplementary initiatives undertaken in 
association with events. This may be convenient for host cities that want to conceal modest achievements, but it is unhelpful for those who favour accountability and evidence based policy. One consequence of adopting the event-themed leverage model is that it provides an excuse for authorities to fold in wider policy initiatives when attempting to justify mega-event projects, whilst consciously leaving them out of mega-event budgets. There is an emerging trend whereby authorities justify a mega-event though claims that other policy initiatives were bolstered by staging events. For example, in the interim evaluation of the London 2012 Games, organisers claimed credit for securing employment for 34,500 workless people via the London Development Agency's Employment and Skills (LEST) Taskforce, concluding: 'in the absence of the Games it is highly unlikely that the LEST 2012 platform would have been developed to its size and structure with the same strategic focus' (DCMS, 2012: 21).

There is a more basic problem with event-themed leverage - so far, there hasn't been much research undertaken on the effectiveness and efficiency of these initiatives. This means we are still unsure about whether this new model is one that works. Conceptually it represents an improvement on existing approaches but the success of projects has yet to be researched comprehensively. One question that is particularly important, but as yet unexplored, is: what value is derived from using event connections in conjunction with certain initiatives? Answering this question requires some attempt to establish a counterfactual position - i.e. what would have happened if the event hadn't been attached to a project (or if the project hadn't been attached to the event). Although such research is notoriously complex there are opportunities to 
compare initiatives that did have event connections with those that did not (and events that did have leverage attached with those that did not).

\section{The beginning of the end for mega-events?}

During the past few years the author of this paper has attended numerous public events where those involved in delivering the London 2012 Games project were required to present (and justify) their work. The audience for these outreach events usually included some people who came to voice their opposition to the event. Over time, opponents have listened to the justifications for the project and heard the ways officials have tried to fend off questions about the questionable record of megaevents. In doing so, these opponents developed an interesting new line of argument. Their position is simple. If mega-events can only be justified by attaching various parallel projects to them that help to lever better outcomes, why can't we have the parallel projects without the mega-events? If the mega-events are the expensive element, and the aspect that causes opportunity costs, displacement and disruption, why not dispose of the unhelpful mega-event element and refocus resources on good wider policies? It is a strong argument, especially when coupled with the demand by some commentators for a return to more modest events that don't make overblown legacy promises they can't keep (McCartney et al., 2010). So, although we have seen a shift from 'events as policy initiatives' to a synthesis of 'events and policy initiatives ', there is perhaps justification for a new separation of events and policy. The leverage model has emerged out of the failure of mega-events to deliver significant positive impacts. Rather than finding a new way to justify events, an alternative is to change direction completely and return to an approach where events 
are regarded simply as events, and where urban objectives are addressed directly rather than through the medium of events. The counter argument is, of course, that events are unprecedented opportunities to achieve certain goals. But if event leveraging is to be justified there needs to be more research exploring these unique opportunities that events supposedly provide. Particular attention needs to be devoted to identifying the circumstances in which events are the most effective way of achieving wider policy goals (and the circumstances in which events strategies should be avoided).

\section{Conclusions}

This paper has attempted to critically evaluate the concept of leverage, an approach that involves a more advanced way of using mega-events strategically. Event-themed leverage initiatives help to turn lazy rhetoric about the transformative power of events into projects that can deliver positive effects. This type of leverage can help to extend the reach of events so that benefits are felt by a wider group of beneficiaries in a wider set of policy fields. However, the paper has also outlined the emerging criticisms of this 'new' way of approaching events. The paper has identified the danger that some leverage initiatives are adopted and publicised merely for public relations reasons to fend off criticism about event projects more generally. Spending on these projects is usually dwarfed by the spending on event venues and other aspects of event delivery. Leverage projects are often adopted because of the need to bring local communities 'onside' and they are cited by event organisers when criticism is forthcoming about projects being imposed on communities, wasteful spending on facilities or the lack of local benefits. However, these criticisms are not 
necessarily inherent problems with the leverage model. Instead they are criticisms of the rather limited way that leverage has been adopted thus far. Projects associated with Commonwealth Games in Manchester (Smith and Fox, 2007) and Melbourne (Kellett et al., 2006); and with Olympic and Paralympic Games staged in Vancouver (VanWynsberghe et al., 2012) and London (Mead and Gruneberg, 2013) suggest this may be changing. Event hosts are beginning to take leverage more seriously and have started to shape events projects to lever strategic objectives, rather than retrofitting initiatives into capital projects still best described as exercises in 'conspicuous construction' (Broudehoux, 2010).

This paper has argued that if leveraging is a prominent and organising principle in event planning (rather than an after-thought), and if the budgets for event leveraging start to match those for staging the event, then it might be possible to talk of a new model. More limited approaches, however well meaning, are more likely to function as ways to justify mega-events. If and when we have solid evidence that a more comprehensive approach is being adopted, and that it works, then it might be possible to advocate this new model as the way mega-events should be planned. However, during the course of the paper a number of issues with leveraging have been raised which also need to be addressed. These include practical issues regarding rights to use event branding, funding arrangements and configuring the optimal institutional framework / leadership responsibilities. A more complicated conceptual issue has also emerged from the discussion: if the leveraging model is pursued in its purest form where initiatives exist independently of events, then we may be inadvertently signalling the futility of mega-event projects. At present, mega-events are usually supplemented with smaller leverage initiatives, but if this relationship is turned on its 
head and leveraging becomes the main priority, this may change the parameters of the debate. Mega-events may suddenly be regarded as rather expensive, disruptive and controversial appendages to sophisticated parallel leverage programmes. 


\section{References}

Beard, M. (2011) Community Work Drive Linked to 2012 is Axed. Evening Standard, $1^{\text {st }}$ Feb 2011.

Broudehoux, A. (2010) Images of Power. Architectures of the Integrated Spectacle at the Beijing Olympics. Journal of Architectural Education, 2010, pp.52-62.

Benneworth, P. and Dauncey, H. (2010) International Urban Festivals as a Catalyst for Governance Capacity Building. Environment and Planning C, 28, pp.1083-1100.

Carey, M., Mason, D. and Misener, L. (2011) Social Responsibility and the Competitive Bid Process for Major Sporting Events. Journal of Sport and Social Issues, 35(3), pp.246-263.

Chalip, L. (2004) Beyond Impact: A Generalised Model for Host Community Event Leverage, In B. Ritchie and S. Adair (Eds.) Sports Tourism: Interrelationships, Impacts and Issues (pp.226-252). Clevedon: Channel View.

Chalip, L. (2006) Towards Social Leverage of Sport Events. Journal of Sport \& Tourism, 11, pp.109-127.

DCMS (2012) Meta-Evaluation of the Impacts and Legacy of the London 2012 Olympic Games and Paralympic Games Summary of Report 4: 'Interim Evaluation'. November 2012. 
Dowling, M., Robinson, L., and Washington, M. (2013) Taking Advantage of the London 2012 Olympic Games: Corporate Social Responsibility through Sport Partnerships, European Sport Management Quarterly DOI:10.1080/16184742.2013.774039

Flyvbjerg, B. (2005) Design by Deception. The Politics of Megaproject Approval. Harvard Design Magazine, Spring/Summer 2005, pp.50-59.

Flyvbjerg, B. (2007) Policy and Planning for Large Infrastructure Projects; Problems, Causes and Cures. Environment and Planning B, 34, pp.578-597.

Gibson, O. (2012) London 2012 Olympics were 'absolutely fabulous', says IOC chief. The Guardian 12 August 2012. Available at: http://www.guardian.co.uk/sport/2012/aug/12/london-2012-olympics-absolutelyfabulous\#ixzz2UhSfhWIt

Gonzalez, S (2011) Bilbao and Barcelona 'in Motion'. How Urban Regeneration 'Models' Travel and Mutate in the Global Flows of Policy Tourism. Urban Studies, 48(7), pp.1397-1418.

Gratton, C., Shibli, S. and Coleman, R. (2005) Sport and Economic Regeneration in Cities. Urban Studies, 42(5/6), pp.985-999. 
Hagn, F. and Maennig, W. (2008) Employment effects of the Football World Cup 1974 in Germany, Labour Economics, 15(5), pp.1062-10.

Jenkins, S. (2007) Jowell and Coe have been Duped by the Biggest Over-Selling Scam in History. The Guardian, $2^{\text {nd }}$ March 2007.

Kellett, P., Hede, A-M. and Chalip, L. (2008) Social Policy for Sport Events: Leveraging (Relationships With) Teams from Other Nations for Community Benefit. European Sport Management Quarterly, 8(2), pp.101-121.

Levermore, R. (2011) Sport-for-Development and the 2010 Football World Cup. Geography Compass, 5, pp.886-897.

Legacy Trust UK. Evaluation Report. March 2013.

McCartney, G. et al. (2010) The Health and Socioeconomic Impacts of Major MultiSport Events: Systematic Review (1978-2008). BMJ 2010;340:c2369.

Mead, J. and Gruneberg, S. (2013). Programme Procurement in Construction: Learning from London 2012. London: Wiley-Blackwell.

Newman, H. (1999) Neighborhood Impacts of Atlanta's Olympic Games. Community Development Journal, 34, pp.151-159. 
Nichols, G. and Ralston, R. (2012) Lessons from the Volunteering Legacy of the 2002 Commonwealth Games. Urban Studies, 49(1), pp. 169-184.

O’Brien, D. (2006) Event Business Leveraging: The Sydney 2000 Olympic Games. Annals of Tourism Research, 33(1), pp.240-261.

O'Brien, D. and Chalip, L. (2007) Executive Training Exercise in Sport Event Leverage. International Journal of Culture, Tourism and Hospitality Research, 1(4), pp.296-303.

Olds, K. (1998) Urban Mega-Events, Eviction and Housing Rights: the Canadian Case. Current Issues in Tourism, 1(1), pp.1-47.

Papadimitriou, D. and Apostolopoulou, A. (2009) Olympic Sponsorship and the Creation of Competitive Advantage. Journal of Promotion Management, 15, pp.90117.

Porter, L., Jaconelli, M., Cheyne, J., Eby, D. and Wagenaar, H. (2009) Planning Displacement: The Real Legacy of Major Sporting Events. Planning Theory \& Practice, 10(3), pp.395-418.

Preuss, H. (2007) The Conceptualisation and Measurement of Mega Sport Event Legacies. Journal of Sport and Tourism, 12(3-4), pp. 207-227. 
Smith, A. (2008) Using Major Events to Promote Peripheral Urban Areas: Deptford and the 2007 Tour de France. In J. Ali-Knight et al. International Perspectives of Festivals and Events (pp.3-19). Oxford: Butterworth-Heinemann/Elsevier.

Smith, A. (2009) Spreading the Positive Effects of Major Events to Peripheral Areas. Journal of Policy Research in Tourism, Leisure and Events, 1(3), pp.231-246.

Smith, A. (2012) Events and Urban Regeneration. Abingdon: Routledge.

$\underline{\text { Smith, A. and Fox, T. (2007) From 'Event-Led' to 'Event-Themed' Regeneration: }}$ The 2002 Commonwealth Games Legacy Scheme. Urban Studies, 44(5/6),_pp.1125$\underline{1143 .}$.

VanWynsberghe, R., Derom, I. and Maurer, E. (2012). Social Leveraging of the 2010 Olympic Games: 'Sustainability’ in a City of Vancouver Initiative. Journal of Policy Research in Tourism, Leisure and Events, 4(2), 185-205.

Watt, P. (2013) 'It's not for us'. Regeneration, the 2012 Olympics and the Gentrification of East London. City, 17(1), pp.99-118

Ziakas, V. (2010) Understanding an event portfolio: the uncovering of interrelationships, synergies, and leveraging opportunities. Journal of Policy Research in Tourism, Leisure and Events, 2:2, pp.144-164.

\footnotetext{
i 'sporting events or sports stadia have little or no significant impact on regional income and/or employment' (Hagn and Maennig, 2008: 1063).
} 
ii 'Our review found insufficient evidence to confirm or refute expectations about the health or socioeconomic benefits for the host population of previous major multi-sport events. Benefits from future events - such as the 2012 Olympic Games and Paralympic Games in London or the 2014 Commonwealth Games in Glasgow - cannot be expected to occur automatically'

(McCartney et al., 2010: 7)

iii Azerbaijan, Brazil, Bangladesh, Egypt, Ethiopia, Ghana, Jordan, India, Indonesia, Malaysia, Mozambique, Nigeria, Pakistan, Palau, South Africa, Tanzania, Trinidad \& Tobago, Turkey, Uganda and Zambia. 